\title{
DESIGN OF A TWO-STAGE ELECTROMAGNETIC IMPULSE FORCE CIRCUIT FOR GENE GUN
}

\author{
Pei-Hwa Huang \\ Department of Electrical Engineering, National Taiwan Ocean University, Keelung, Taiwan, R.O.C., \\ b0104@mail.ntou.edu.tw \\ Ping-Yin Chen \\ Department of Electrical Engineering, National Taiwan Ocean University, Keelung, Taiwan, R.O.C.
}

Follow this and additional works at: https://jmstt.ntou.edu.tw/journal

Part of the Engineering Commons

\section{Recommended Citation}

Huang, Pei-Hwa and Chen, Ping-Yin (2011) "DESIGN OF A TWO-STAGE ELECTROMAGNETIC IMPULSE FORCE CIRCUIT FOR GENE GUN," Journal of Marine Science and Technology. Vol. 19: Iss. 6, Article 14.

DOI: $10.51400 / 2709-6998.2212$

Available at: https://jmstt.ntou.edu.tw/journal/vol19/iss6/14

This Research Article is brought to you for free and open access by Journal of Marine Science and Technology. It has been accepted for inclusion in Journal of Marine Science and Technology by an authorized editor of Journal of Marine Science and Technology. 
DESIGN OF A TWO-STAGE ELECTROMAGNETIC IMPULSE FORCE CIRCUIT FOR GENE GUN

Acknowledgements

The authors gratefully acknowledge Mr. F. C. Jhu for his assistance with the testing work and Prof. C. C. Lu for his kind support for this research. 


\title{
DESIGN OF A TWO-STAGE ELECTROMAGNETIC IMPULSE FORCE CIRCUIT FOR GENE GUN
}

\author{
Pei-Hwa Huang* and Ping-Yin Chen*
}

\begin{abstract}
Key words: electric power system, electromagnetic force, electric energy device, capacitor charging and discharging, gene gun power source.
\end{abstract}

\begin{abstract}
The main objective of this paper is to present a design of the power source for gene gun based on the principle of electromagnetic mechanism. The energy stored in capacitors will be discharged toward the electromagnetic device of gene gun for providing micro-projectiles with electromagnetic force to generate the desired impact force, and a specific electronic circuit is to be designed to achieve the coupling between the electromagnetic device and the energy storage capacitor. A gene gun is to be implemented for a testing purpose. In order to reduce the size and the cost of the gene gun, a two-stage electromagnetic control strategy is developed in which a single chip is utilized to control the discharge time of dual capacitors in order to increase the impact force. According to the experimental results, with the same capacitance, the proposed gene gun can generate higher impact force with smaller sizes and lower cost, and the validity and feasibility of the proposed electromagnetically powered gene gun is thus verified.
\end{abstract}

\section{INTRODUCTION}

The gene gun is also known as "particle gun." In the process of genetic engineering, DNA (Deoxyribonucleic Acid) is first extracted from donor cells. Then we divide DNA and vectors with restrictive enounce, connect exogenous gene of DNA fragments to carriers with DNA ligase, and thus form recombinant DNA molecules. The recombinant DNA molecules are then delivered into receptor molecules with gene guns in which small gold or tungsten genes coated with DNA are accelerated to the high speed of $430 \mathrm{~m} / \mathrm{sec}$ and for penetrating cell walls and/or cell membranes. In this way, the

Paper submitted 01/31/11; accepted 04/28/11. Author for correspondence: Pei-Hwa Huang (e-mail:B0104@mail.ntou.edu.tw).

"Department of Electrical Engineering, National Taiwan Ocean University, Keelung, Taiwan, R.O.C.
DNAs are delivered into target cells and the process of gene transfer is thus completed. Due to the chemical inactivity of the pure gold, such processes will not bring forth toxicity to the receptor. The first application of this technology was for gene transfer of plants such as maize, nicotiana, onion, gladiolus, asparagus, soybean, paddy rice, wheat, sugar cane, cotton and grapes $[8-11,18,31]$. Later on it was applied to microorganism and mammalian experiment systems. With gene guns, researchers had successfully transferred genes into culture cells such as bacillus, skin epidermis, skin dermis, muscle, liver, pancreas, hematopoietic stem cells (HSC), prostate cancer cells, chest epithelial cells, nerve cells, melanoma cells, sarcoma cell and other living tissues [4, 7, 19, 25, 26, 28-30]. Therefore, as a branch of biotechnology, gene gun technology not only promotes the success but also enhances the technical capability of biotechnology.

In 1987, Professor John Sanford (Cornell University, U.S.) invented a gunpowder-driven gene gun for launching microprojectiles [21]. However, with gunpowder as a power source, the gene gun could result in issues of pollution, loud noise, complicated auxiliary equipments, and safety concern $[21,22$, 32]. Hence, researchers have developed other types of gene guns driven by high voltage discharge $[5,14,15,33]$, compressed gas $[1,12,13,16,17,20,23,24]$ centrifugal force $[23$, $24]$, and static electricity [23, 24]. Each of those gene guns has certain drawbacks. For gene gun driven by high voltage discharge, the accelerator is driven by the heated gas (evaporated from a small droplet of water) generated by the discharge of high voltage ( $24 \mathrm{kV}-\mathrm{dc})$, and yet this is a very noisy approach and the gas with high speed and high temperature generated by the shock wave may kill the cells. The gene gun driven by compressed gas usually uses expensive helium, and the exhaust of such high-pressure gas might cause additional problems. The gene gun driven by centrifugal force utilizes a high-speed rotating wheel, which generates an adhesive or breakaway micro particle with an ultra high speed. When this micro particle breaks away from the rotating wheel, it follows the path in a tangential direction; however, controlling such impact force is not easy. The gene gun driven by static electricity utilizes electrostatic charged micro particles for the acceleration of sub-atoms, and it is also not easy to control such impact force. 
The process of gene transfer is essentially the process of delivering exogenous genes into some complete living cells or tissue with small gold or tungsten powder particles coated with DNA. The "particles" are small sticky gold or tungsten particles with the diameter of 0.4-2.0 $\mu \mathrm{m}$. Because the "particles" cannot be accelerated directly, they must be attached to projectiles or diaphragms such that the DNA may be accelerated along with these objects to high velocity and then transferred into acceptors. Although the DNA transfer by impact with the micro-particle acceleration system has been developed for about 20 years, due to the complexity and difficulty of measurement, there has been not much literature related to the formation of impact force and the speed of micro-particles.

In this paper, based on the principles of electromagnetic mechanism, a new type of power source, with energy first stored in capacitors and then discharged, is proposed for providing micro projectiles with electromagnetic force to generate the desired impact force. In order to reduce the size and the cost of the gene gun, a two-stage electromagnetic control strategy is developed in a way by which a single chip is utilized to control the discharge time of dual capacitors to increase the impact force. The implemented gene gun has an advantage over the above-mentioned types of gene guns with lower cost and easy operation. This paper is organized as follows. In Section 2, fundamentals on electromagnetic impacts are discussed. In Section 3, the details of circuit design and simulation are described. Then the experimental results are shown in Section 4 as the demonstration of the validity and feasibility of the control circuit for the proposed gene gun, and as the proof that the multi-stage electromagnetic control strategy can indeed improve the impact force and reduce the device size.

\section{ELECTROMAGNETIC IMPACT FORCE}

According to the Faraday's law of electromagnetic induction $[3,6]$, in a static closed loop coil the induced voltage $(e)$ equals to the negative rate of time variation of the magnetic flux $(\phi)$ flowing through this loop and can be shown as

$$
e=-\frac{d \phi}{d t}
$$

where $\phi$ and $t$ denote the magnetic flux (wb) and time (sec), respectively. The negative sign in (1) guarantees that current generated by the induced voltage follows in the direction against the variation of magnetic flux. When there are $N$ turns in the coil, the induced voltage can be found as

$$
e=-\frac{d \lambda}{d t}=-\frac{d(N \phi)}{d t}=-N \frac{d \phi}{d t}
$$

where $\lambda=N \phi$ is the flux linkage (wb).

When a current $i(\mathrm{~A})$ flows through a coil with constant inductance $L(\mathrm{H})$, from (2) the induced voltage will be

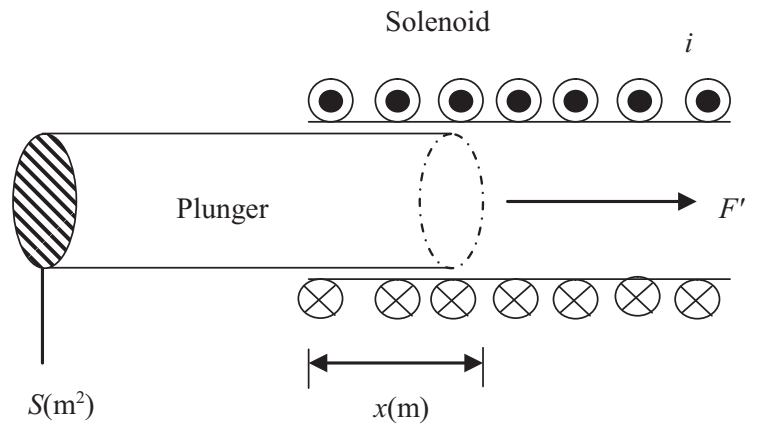

Fig. 1. Solenoid with N-turn coil and plunger.

$$
\begin{gathered}
e=-L \frac{d i}{d t}=-\frac{d(\lambda)}{d t} \\
d \lambda=L d i=d(L i) \\
L=\lambda / i
\end{gathered}
$$

In a magnetic system, if the magnetomotive force is $\mathcal{F}=\mathrm{Ni}$ (A-t), then the magnetic flux flowing in the magnetic circuit will be $\phi=\mathcal{F} / \mathcal{R}=\mathcal{F P}($ wb) with $\mathcal{R}$ and $\mathcal{P}$ denoting the reluctance and permeance of the system, respectively. Then the inductance $L(\mathrm{H})$ can be found as

$$
L=\frac{\lambda}{i}=\frac{N \phi}{i}=\frac{N(\mathcal{F} \mathcal{P})}{i}=\frac{N(N i) \mathcal{P}}{i}=N^{2} \mathcal{P}
$$

Consider the magnetic system shown in Fig. 1 where the plunger made of soft iron is moving inside the solenoid. The solenoid carries a current $i(\mathrm{~A})$ with $N$ turns per unit length, and the plunger has cross-sectional area $S\left(\mathrm{~m}^{2}\right)$ and permeability $\mu$. As the plunger moves in the solenoid with a depth of $x(\mathrm{~m})$, the permeance $P$ becomes

$$
\begin{gathered}
\mathcal{P}=\mu \frac{S}{x}=\mu_{0} \mu_{\mathrm{r}} \frac{S}{x} \\
L=N^{2} \mathcal{P}=\frac{\mu_{0} \mu_{\mathrm{r}} N^{2} S}{x}
\end{gathered}
$$

where $\mu_{0}=4 \pi \times 10^{-7}$ (wb/At-m) is the permeability of free air and $\mu_{\mathrm{r}}$ is the relative permeability of the soft iron. The inductance of the part of the solenoid without the plunger is

$$
L=N^{2} \mathcal{P}=\frac{\mu_{0} N^{2} S}{x}
$$

The magnetic force varies with the different position of the plunger inside the solenoid. The solenoid will generate an attractive force $F^{\prime}$ (Newton) to pull the plunger inward. If the distance of inward movement is assumed as $x$, then the mag- 
netic force will be [6]

$$
F^{\prime}=-\frac{d W}{d x}
$$

where $W$ denotes the magnetic field energy stored in the solenoid and can be represented as

$$
W=\frac{L i^{2}}{2}=\frac{N^{2} \mathcal{P} i^{2}}{2}=\frac{(N i)^{2} \mathcal{P}}{2}
$$

The attractive force becomes

$$
F^{\prime}=-\frac{d W}{d x}=-\frac{1}{2} \frac{d(N i)^{2} \mathcal{P}}{d x}=-\frac{1}{2}(N i)^{2} \frac{d \mathcal{P}}{d x}
$$

From (7),

$$
\frac{d P}{d x}=\frac{d}{d x}\left(\mu \frac{S}{x}\right)=-\mu \frac{S}{x^{2}}
$$

Therefore,

$$
F^{\prime}=-\frac{1}{2}(N i)^{2} \frac{d \mathcal{P}}{d x}=-\frac{1}{2}(N i)^{2}\left(-\mu \frac{S}{x^{2}}\right)=\frac{\mu(N i)^{2} S}{2 x^{2}}
$$

The attractive force $F^{\prime}$ will decrease as $x$ increases.

To determine the capacitance $C$ of the capacitor, consider the single phase bridge rectifier in the capacitor input filter circuit. Usually every rectifier diode will be conductive for $3 \mathrm{~ms}$ to supply electricity to the output, and for the rest $7 \mathrm{~ms}$ the electricity will be supplied by the filter capacitor. The energy storage of the capacitor will fluctuate by about $20 \%$. For every half power cycle, output of the capacitor, i.e. $20 \%$ of the stored energy, is provided corresponding to $70 \%$ of the output power $P_{\mathrm{o}}$, and the power provided in advance for the output within one second is [2]

$$
0.2 \times 2 f \times \frac{1}{2} C V^{2}=0.7 P_{\mathrm{o}}
$$

Then the capacitance will be

$$
C=\frac{7 P_{\mathrm{o}}}{2 V^{2} f}
$$

where $V$ and $f$ denote the peak voltage and frequency, respectively.

\section{DESIGN AND SIMULATION OF CONTROL CIRCUIT}

\section{Design of Control Circuit}

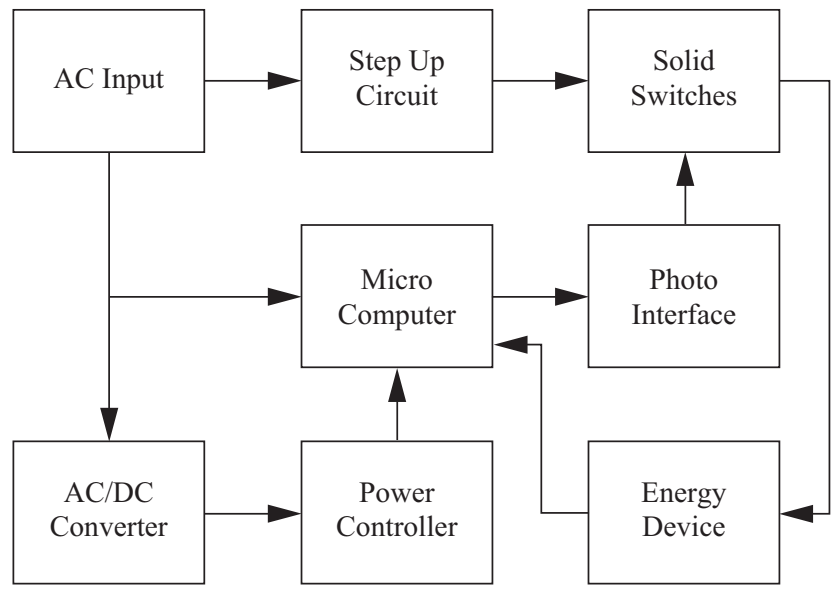

Fig. 2. Structure of the control system of the particle gun.

The control circuit of the gene gun is composed of an external circuit and a microcomputer to drive the electromagnetic energy device. The gene gun utilizes the capacitor to store energy and to discharge to the electromagnetic solenoid in a very short time such that a strong impact force is generated. The major components of the external circuit include a DC current source, multiple optoelectronic interfaces, multiple energy storing capacitors, two sets of solid-state switch circuit, a zero voltage control circuit, a power source control circuit, a voltage comparator circuit and an electric energy compensation circuit. Fig. 2 shows the structure of the gene gun control circuit in this study. With the control of microcomputer program, we can deliver continuous impact force in order to solve the issue of inadequate impact force of the traditional single impact approach.

The microcomputer and the optoelectronic interface circuit consisting of two optoelectronic interfaces, as shown in Fig. 3, are designed to facilitate the control the discharge time of two sets of capacitors. When the microcomputer sends out electric energy compensation signal $\mathrm{C}$, in the meantime it also sends out signals for the activation of optoelectronic interfaces. When the output is completed, the electric energy compensation signal $\mathrm{C}$ will be stopped and zero voltage circuit control signal $\mathrm{D}$ will be sent out to stop the output of circuit. When the switch (S5) is (ON), the microcomputer will send zero voltage circuit control signal D to stop the circuit output; this process from the activation to the termination of program by microcomputer is the so-called programmable control. The solid stage switch circuit is shown in Fig. 4. When a single optoelectronic interface is activated, the SCR of the corresponding single set of solid state switch will be triggered to be "ON" such that the capacitor can immediately discharge to the electromagnetic device to achieve the output of electromagnetic force. And since there are two sets of solid state switch circuits, continuous output of electromagnetic force can be achieved.

Microcomputer device uses single chip to control the discharge time. The functional diagram of single chip control 


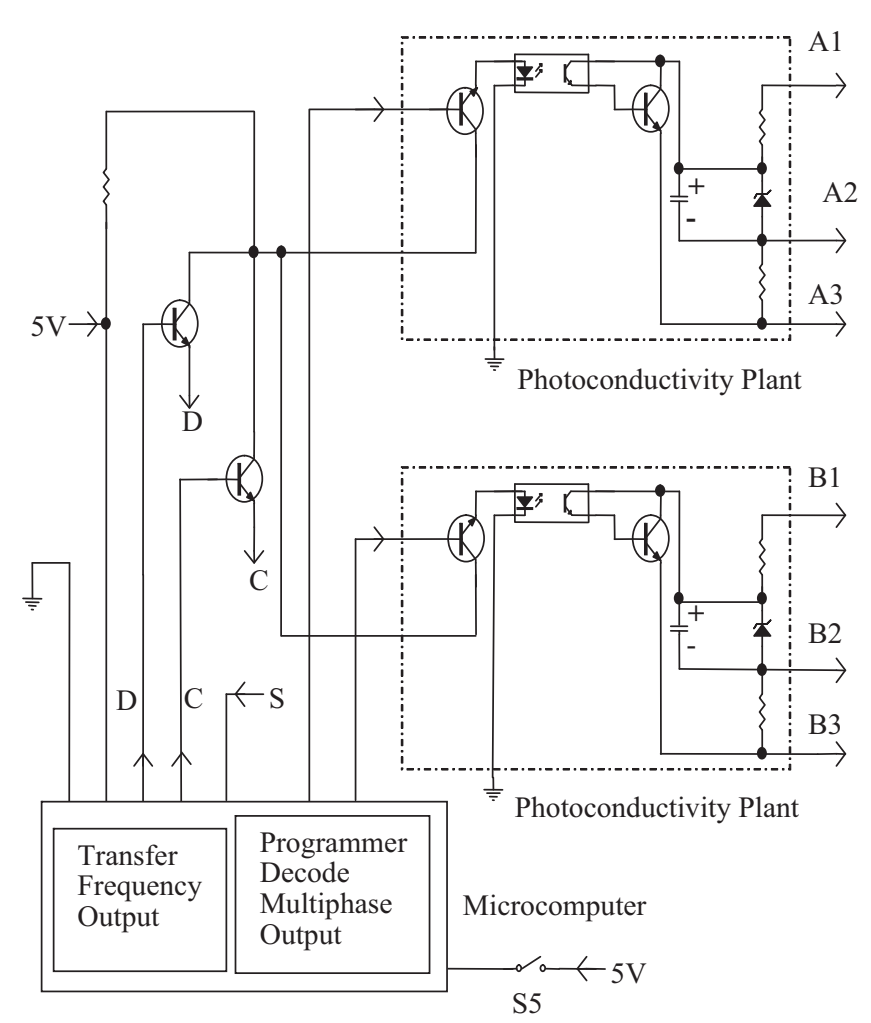

Fig. 3. Microcomputer and optoelectronic interface circuit.

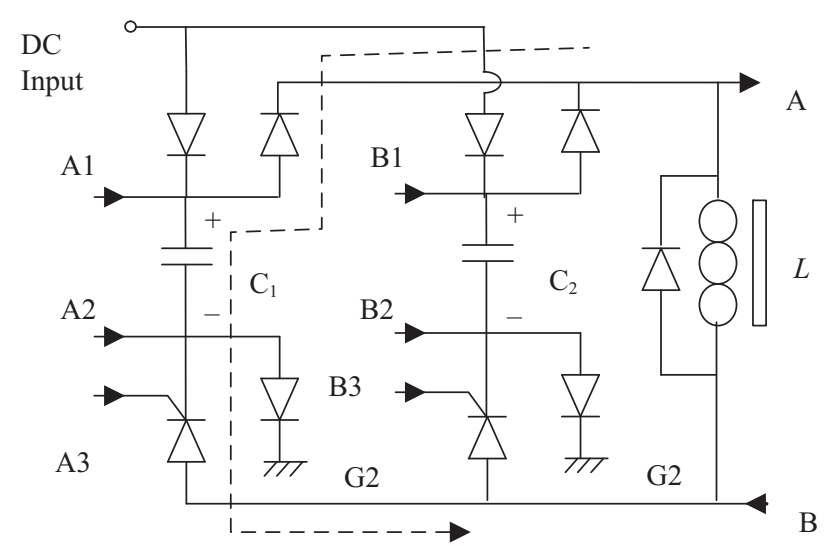

Fig. 4. Solid switches.

system is shown in Fig. 5. The control approach is in the following way. After the single chip receives activation signal (ON/OFF switch) from external users, it sends out $N$ signals triggering the discharge of capacitors following the order and then stops.

\section{Circuit Simulation}

When the plunger enters solenoids, anti-magnetic force will be generated. For further enhancement of impact force, we develop a multi-stage electromagnetic control strategy and utilize the PSPICE software to simulate the discharge voltage and current of the multi-stage electromagnetic control circuit.

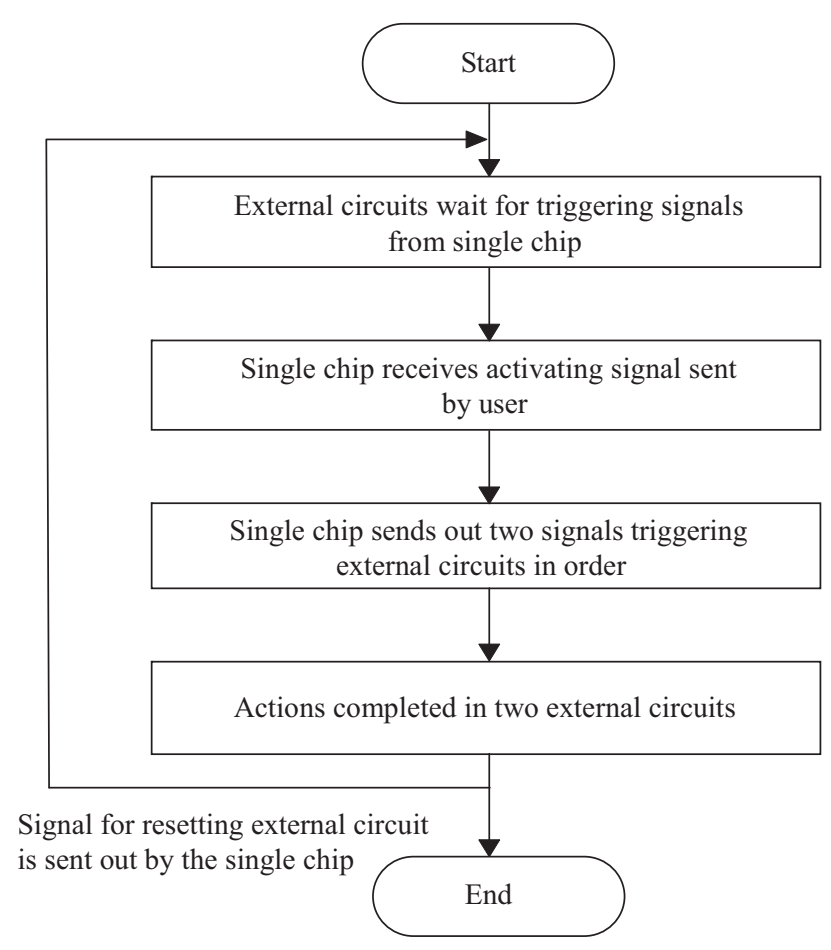

Fig. 5. Functional diagram of single chip control system.

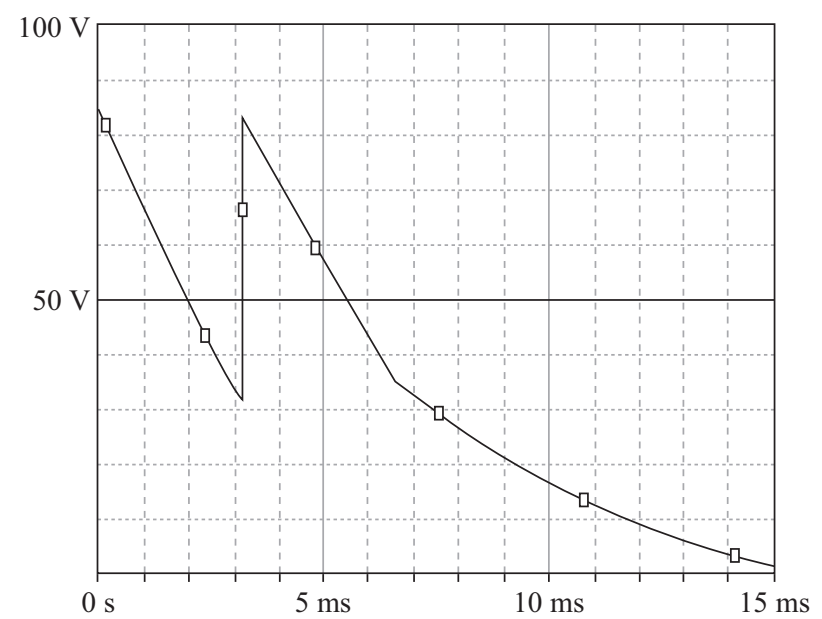

Fig. 6. PSPICE simulation curve of discharge voltage of two-capacitor two-stage electromagnetic control circuit.

The PSPICE simulation result of discharge voltage curves of the two-stage double-capacitor electromagnetic control circuit is shown in Fig. 6. These two capacitors have been precharged to a certain potential level. When the first capacitor is discharged to approximately one half of the discharge voltage, the second capacitor is introduced to instantly raise the discharge voltage for the second discharge. The PSPICE simulation result of discharge current curves of the two-stage double-capacitor electromagnetic control circuit is shown in Fig. 7. Discharge current will rise along with the spike of discharge voltage to generate more impact force. 


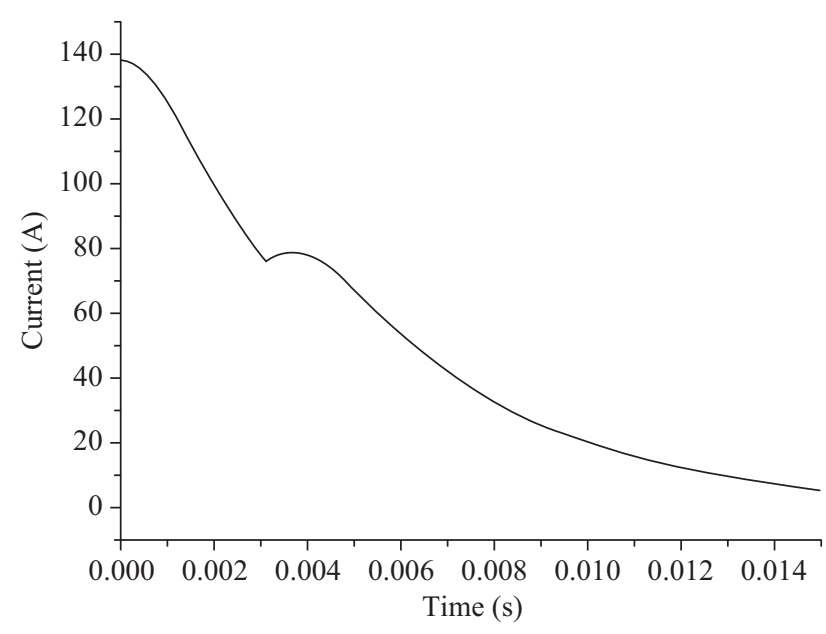

Fig. 7. PSPICE simulation curve of discharge current of two-capacitor two-stage electromagnetic control circuit.

\section{EXPERIMENTAL RESULTS}

\section{Experiment I}

Based on aforementioned circuit characteristics and design considerations, we are to implement an electromagnetic gene gun by modifying the interior structure of an electric tacker as the impact device for the gene gun. The solenoid of the impact device has resistance of $0.68 \Omega$ and inductance of $3.07 \mathrm{mH}$, with power at $1000 \mathrm{~W}, \mathrm{DC}$ input voltage at $150 \mathrm{~V}$, and frequency at $60 \mathrm{~Hz}$. The minimum capacitance $C$ can be calculated from (16) as:

$$
C=\frac{7 P_{\mathrm{o}}}{2 V^{2} f}=\frac{7 \times 1000}{2 \times 150^{2} \times 60}=2593 \mu \mathrm{F}
$$

Energy stored in the capacitor will be instantly discharged to the impact device such that the generated electromagnetic force will provide impact force for projectiles. This will be compared with the requirements for the pressure of gene guns [27] in order to verify the validity and feasibility of the theoretical analysis of this study.

Measurements are conducted by using a piezoelectric force sensor. Shown in Fig. 8 is the curve of pressure per unit area converted from the measured force sensor voltage under different discharge voltages of a single capacitor (with different capacitance), where the pressure unit is psi, the $x$-axis is the discharge voltage of capacitors, and the $y$-axis is the impact force of gene guns. From this figure we can observe that the curves of impact forces generated by different values of capacitance are quite similar, while the only difference is the discharge voltage for generating the maximum impact pressure. The smaller the capacitance, the larger the discharge voltage is required to generate the same impact force. The discharge voltage is roughly proportional to the output impact

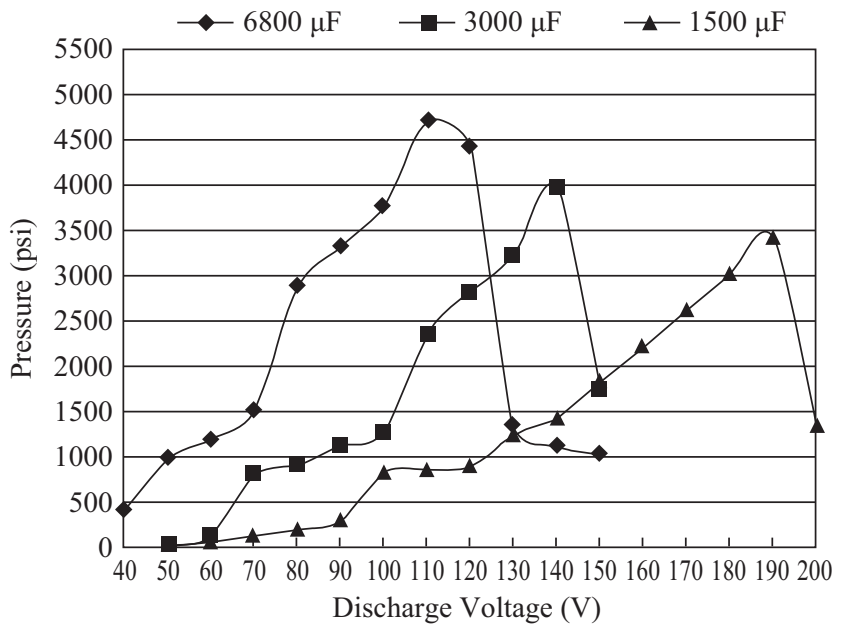

Fig. 8. Curves of pressure per unit area converted from output voltage of single-stage impact force sensor.

force. Larger capacitance will generate larger impact force under the same discharge voltage. For smaller capacitance, larger discharge voltage is required to generate larger impact force. However, when the discharge voltage is larger than the critical value, the output impact force will actually decrease due to the counter force holding the plunger when it enters the solenoid coil. Therefore, the larger the capacitance, the smaller the critical voltage for this phenomenon will get.

\section{Experiment II}

In order to reduce the size and cost of the gene gun, we are to design a multi-stage electromagnetic control circuit by utilizing:

(a) energy stored in a $3000 \mu \mathrm{F} / 200 \mathrm{~V}$ capacitor to be instantly discharged to the electromagnetic device of the gene gun;

(b) single chip 8051 to control the input time of two 1500 $\mu \mathrm{f} / 200 \mathrm{~V}$ capacitors to generate electromagnetic force to the electromagnetic device of the gene gun.

The impact forces generate by (a) and (b) will be compared to verify that the multi-stage electromagnetic control is superior to the single-stage electromagnetic control. The specifications are:

\section{AC input voltage: $110 \mathrm{~V}$;}

Capacitors: $3000 \mu \mathrm{F} / 200 \mathrm{~V}^{*} 1,1500 \mu \mathrm{F} / 200 \mathrm{~V} * 2$;

Impact device: coil resistance $0.68 \Omega$, inductance $3.07 \mathrm{mH}$.

Fig. 9 shows two response curves of the discharge voltage of the two-capacitor two-stage continuous discharge under different timing for capacitor switching. The difference lies in the timing for capacitor switching. From the figure we can see that once the second capacitor is switched for discharging, the voltage will rapidly rise and then decrease. Fig. 10 depicts the current response of the continuous discharge of double 


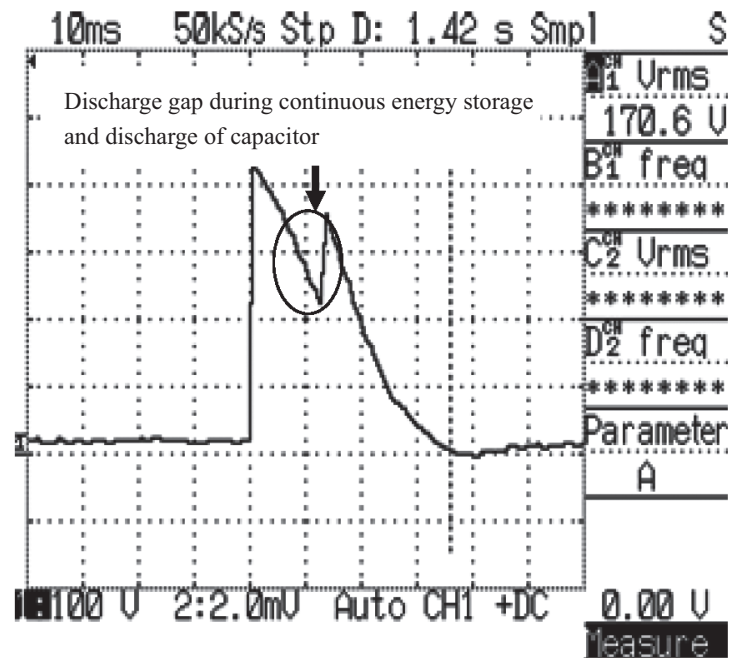

(a)

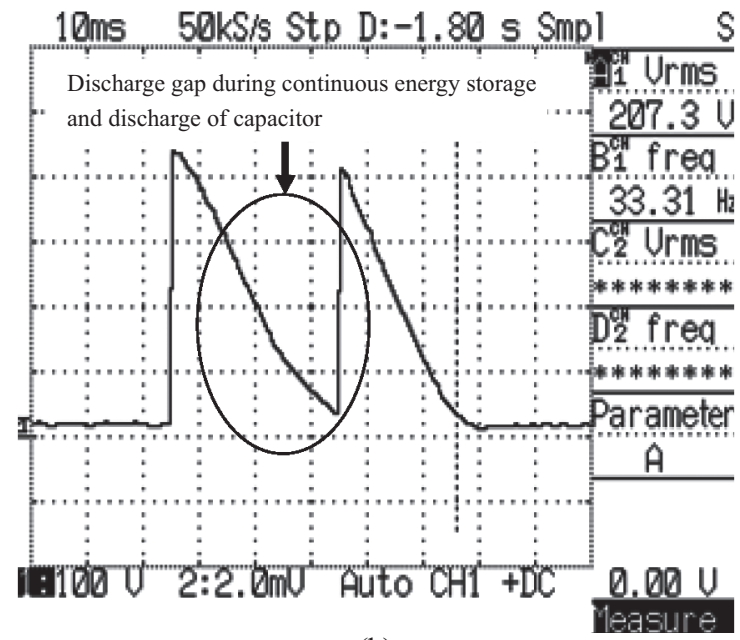

(b)

Fig. 9. Voltage of the two-capacitor two-stage continuous discharge.

capacitors at $70 \mathrm{~V}$. Similarly, the current goes up when the second capacitor is switched for discharging and then goes down.

Fig. 11 shows the curves of pressure per unit area converted from the force sensor voltages of single and double capacitors (with same total capacitance) measured under different discharge voltages, where the unit for pressure is psi, $x$-axis is the discharge voltage of capacitors, and $y$-axis is the impact force of gene guns. From this figure we can see that when discharge voltage is lower than $80 \mathrm{~V}$, single capacitor generates larger impact force; but when this voltage is between $80 \mathrm{~V}$ and $130 \mathrm{~V}$, the impact force generated by multi-stage control method is larger; when this voltage continues to rise until surpassing certain value, the output impact force will actually decrease due to the counter force holding the plunger when it enters the solenoid coil. This result is the same as that observed in Experiment I.

Usually the pressure of gene guns used for the transplant of

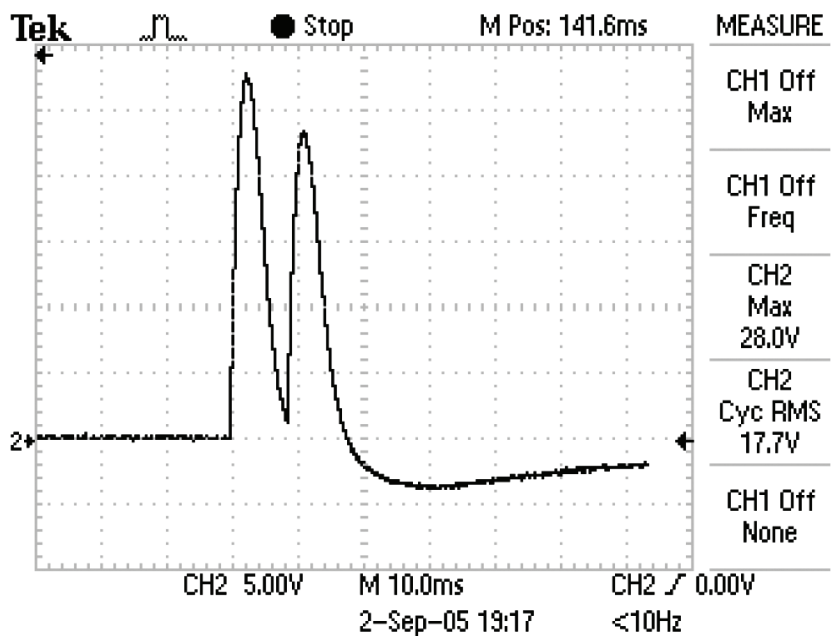

Fig. 10. Current of the two-capacitor continuous discharge at $70 \mathrm{~V}$.

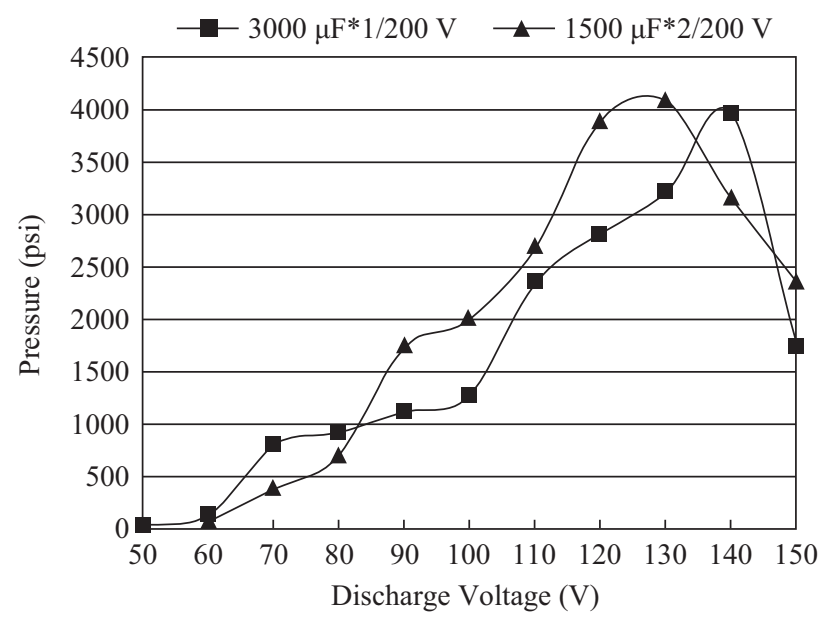

Fig. 11. Curves of pressure per unit area converted from output voltage of two-stage impact force sensor.

plant genes is around 450-2200 psi [27]. The gene gun developed in this study provides pressure over 4500 psi with single capacitor of $6800 \mu \mathrm{F}$ and discharge voltage at $110 \mathrm{~V}$. Therefore it already meets the requirement of maximum pressure for plant gene transfer by providing impact force covering larger range, and thus outperforms most types of gene guns available on the market. In order to reduce the size and cost of the gene gun, we further design the multi-stage electromagnetic control circuit and utilizes single chip 8051 to control the capacitor discharge time. The experimental results have proven that the multi-stage electromagnetic control is superior to the single-stage electromagnetic control.

\section{CONCLUSION}

In this paper, based on the theory of electromagnetism, a gene gun has been proposed by utilizing capacitors as the storage device for supplying electric energy. Besides the 
advantages of low price and convenient operation, the proposed gene gun also provides impact force covering a larger range. The pressure of common gene guns available on the market is around $450-2200 \mathrm{psi}$, while our gene gun can provide pressure above 4500 psi with the capacitor of $6800 \mu \mathrm{F}$. In order to reduce the size and cost of the gene gun, a multi-stage electromagnetic control strategy has been developed to enhance the impact force. According to the experimental results, with the same capacitance, the proposed gene gun can generate higher impact force with a smaller size and lower cost, and thus the feasibility of the proposed electromagnetically powered gene gun is verified.

\section{ACKNOWLEDGMENTS}

The authors gratefully acknowledge Mr. F. C. Jhu for his assistance with the testing work and Prof. C. C. Lu for his kind support for this research.

\section{REFERENCES}

1. Chao, S.-C., Analysis of the Performance of the Gas Driven Particle Acceleration System, Master Thesis, Department of Mechanical Engineering, Chung Hsing University, Taichung, Taiwan (2008).

2. Chen, Y., Capacitors and Applications, Science Press, Beijing (2005).

3. Cheng, D. K., Fundamentals of Engineering Electromagnetics, Addison Wesley, Reading, MA (1993).

4. Cheng, L., Ziegelhoffer, P. R., and Yang, N. S., "In vivo promoter activity and transgene expression in mammalian somatic tissues evaluated by using particle bombardment," Proceedings of the National Academy of Sciences of the United States of America, Vol. 90, No. 10, pp. 4455-4459 (1993).

5. Christou, P., McCabe, D. E., and Swain, W. F., "Stable transformation of soybean callus by DNA-coated gold particles," Plant Physiology, Vol. 87, No. 3, pp. 671-674 (1988).

6. Fitzgerald, A. E., Kingsley, Jr., C., and Umans, S. D., Electric Machinery, Sixth Edition, McGraw-Hill, New York (2003).

7. Heiser, W. C., "Gene transfer into mammalian cells by particle bombardment," Analytical Biochemistry, Vol. 217, No. 2, pp. 185-196 (1994).

8. Kamo, K., Blowers, A., Smith, F., and Van Eck, J., "Stable transformation of Gladiolus by particle gun bombardment of cormels," Plant Science, Vol. 110, No. 1, pp. 105-111 (1995).

9. Klein, T. M., Fromm, M., Weissinger, A., Tomes, D., Schaaf, S., Sletten, M., and Sanford, J. C., "Transfer of foreign genes into intact maize cells with high-velocity microprojectiles," Proceedings of the National Academy of Sciences of the United States of America, Vol. 85, No. 12, pp. 43054309 (1988).

10. Klein, T. M., Harper, E. C., Svab, Z., Sanford, J. C., Fromm, M. E., and Maliga, P., "Stable genetic transformation of intact nicotiana cells by the particle bombardment process," Proceedings of the National Academy of Sciences of the United States of America, Vol. 85, No. 22, pp. 8502-8505 (1988).

11. Li, B. and Wolyn, D. J., "Recovery of transgenic asparagus plants by particle gun bombardment of somatic cells," Plant Science, Vol. 126, No. 1, pp. 59-68 (1997).

12. Lin, H. J., Huang, K. J., Yang, H. T., and Chen, W. C., "Low pressureaccelerated particle gene gun," U.S. Patent 6436709B1 (2002).

13. Lin, H. J., Wang, Y. C., and Chen, C. H., "Low pressure gas accelerated gene gun," U.S. Patent 7638332B2 (2009).

14. McCabe, D. E., Swain, W. F., and Martinell, B. J., "Pollen-mediated plant transformation," E.P. Patent 0270356A2 (1988).

15. McCabe, D. E., Swain, W. F., Martinell, B. J., and Christou, P., "Stable transformation of soybean (glycine max) by particle acceleration," Nature Biotechnology, Vol. 6, No. 8, pp. 923-926 (1988).

16. Morikawa, H., Iida, A., and Yamada, Y., "Transient expression of foreign genes in plant cells and tissues obtained by a simple biolistic device (particle-gun)," Applied Microbiology and Biotechnology, Vol. 31, No. 3, pp. 320-322 (1989).

17. Nabulsi, S. M., Page, N. W., Duval, A. L., Seabrooks, Y. A., and Scotts, K. J., "A gas-driven gene gun for microprojectile methods of genetic engineering," Measurement Science and Technology, Vol. 5, No. 3, pp. $267-$ 274 (1994).

18. Oard, J. H., Paige, D. F., Simmonds, J. A., and Gradziei, T. M., "Transient gene expression in maize, rice, and wheat cells using an air gun apparatus," Plant Physiology, Vol. 92, No. 2, pp. 334-339 (1990).

19. O’Brien, J. A., Holt, M., Whiteside, G., Lummis, S. C. R., and Hastings, M. H., "Modifications to the hand-held gene gun: improvements for in vitro biolistic transfection of organotypic neuronal tissue," Journal of $\mathrm{Neu}$ roscience Methods, Vol. 112, No. 1, pp. 57-64 (2001).

20. Sanford, J. C., DeVit, M. J., Bruner, R. F., Sewell, N. J., Johnston, S. A., and Durham, N. C., "Method and apparatus for introducing biological substances into living cells," U.S. Patent 5204253 (1993).

21. Sanford, J. C., Klein, T. M., Wolf, E. D., and Allen, N., "Delivery of substances into cells and tissues using a particle bombardment process," Particulate Science and Technology, Vol. 5, No. 1, pp. 27-37 (1987).

22. Sanford, J. C., Wolf, E. D., and Allen, N. K., "Apparatus for delivering substances into cells and tissues in a non-lethal manner," E.P. Patent 0331855A3 (1989).

23. Sanford, J. C., Wolf, E. D., and Allen, N. K., "Method for transporting substances into living cells and tissues and apparatus therefor," U.S. Patent 4945050 (1990).

24. Sanford, J. C., Wolf, E. D., and Allen, N. K., "Method for transporting substances into living cells and tissues and apparatus therefor," U.S. Patent 5036006 (1991).

25. Shark, K. B., Smith, F. D., Harpending, P. R., Rasmussen, J. L., and Sanford, J. C., "Biolistic transformation of a procaryote, Bacillus megaterium," Applied Environmental Microbiology, Vol. 57, No. 2, pp. 480485 (1991).

26. Sun, W. H., Burkholder, J. K., Sun, J., Culp, J., Turner, J., Lu, X. G., Pugh, T. D., Ershler, W. B., and Yang, N. S., "In vivo cytokine gene transfer by gene gun reduces tumor growth in mice," Proceedings of the National Academy of Sciences of the United States of America, Vol. 92, No. 7, pp. 2889-2893 (1995).

27. Transgenic Plant Lab, Academia Sinica, Retrieved Jan. 15, 2011 from http://transplant.sinica.edu.tw/facility/PDS-1000\%20protocols/.

28. Wellmann, H., Kaltschmidt, B., and Kaltschmidt, C., "Optimized protocol for biolistic transfection of brain slices and dissociated cultured neurons with a hand-held gene gun," Journal of Neuroscience Methods, Vol. 92, No. 1, pp. 55-64 (1999).

29. Williams, R. S., Johnston, S. A., Riedy, M., DeVit, M. J., McElligott, S. G., and Sanford, J. C., "Introduction of foreign genes into tissues of living mice by DNA-coated microprojectiles," Proceedings of the National Academy of Sciences of the United States of America, Vol. 88, No. 7, pp. 27262730 (1991).

30. Yang, N. S., Burkholder, J., Roberts, B., Martinell, B., and McCabe, D., "In vivo and in vitro gene transfer to mammalian somatic cells by particle bombardment," Proceedings of the National Academy of Sciences of the United States of America, Vol. 87, No. 24, pp. $9568-9572$ (1990).

31. Yang, N. S. and Russell, D., "Maize sucrose synthase-1 promoter directs phloem cell-specific expression of Gus gene in transgenic tobacco plants," Proceedings of the National Academy of Sciences of the United States of America, Vol. 87, No. 11, pp. 4144-4148 (1990).

32. Yao, S. and Liu, Z., "Transfer genes method and particles gun," C.N. Patent 1052695A (1991).

33. Yao, S., Qin, Z., Chen, Z., Sun, Y., Liu, Z., Liu, Z., Zhang, D., Xu, X., and Zuo, G.,"Bombardment device of gene with high-voltage discharge," C.N. Patent 1054796A (1991). 